\title{
LOS ARCHIVOS DEL DOLOR: \\ ENSAYOS SOBRE LA VIOLENCIA Y EL RECUERDO \\ EN LA SUDÁFRICA CONTEMPORÁNEA \\ Alejandro Castillejo
}

Bogotá: Universidad de los Andes

2009, $430 \mathrm{p}$.

$\downarrow$ ú

ablar de la República de Sudáfrica se hizo frecuente en los últimos veinte años, en escenarios académicos y políticos, especialmente por el protagonismo de las luchas sociales que libraron miles de personas contra el apartheid y la aparente transición política hacia la democracia que vivió el país. Al protagonismo de estas luchas, se sumó un activismo antiapartheid a escala mundial que fue replicándose como modelo transcontinental. Un modelo conectado al nuevo evangelio humanitario de la reconciliación que se nutrió de acontecimientos transcendentales, como la liberación de Mandela, el Premio Nobel de la Paz compartido entre Mandela y De Klerk, el período de transición, las primeras elecciones presidenciales de Sudáfrica en I994 y la creación de la Comisión de la Verdad y la Reconciliación. Sobre este país se activó una producción titánica de escritos. Al igual que en Colombia, la guerra y el trauma generaron no solo muertos sino también expertos de todo tipo. La experticia colonizó y nombró un campo de estudios sobre la naturaleza y los efectos del apartheid, que fue diseminando su semilla por el mundo con estudios monográficos sobre el dolor, la justicia transicional, las comisiones de verdad y la resolución de conflictos.

Frente a ese panorama, Sudáfrica sería, a primera vista, un escenario de campo y de investigación saturado y, en no pocas ocasiones, violentado por una ciencia social extractiva. Sin embargo, la verdad es que no dejan de martillar en nuestros oídos algunas preguntas pendientes de respuestas más claras, por ejemplo, ¿cómo escribir acerca del silencio, la invisibilidad y la muerte?, ¿para qué desafiar los cánones de la escritura antropológica, sociológica o histórica acerca de estos tópicos?, ¿qué significados e implicaciones tendría concebir las múltiples maneras y trazos en los que el pasado habita el presente y viceversa?, ¿cómo, en la sociedad sudafricana, con violencias acumuladas y 
silencios reciclados, logra archivarse el dolor y hacerse inteligible lo ininteligible? Precisamente a la deconstrucción del sentido y los alcances de estos interrogantes, Alejandro Castillejo dedica su esfuerzo en este libro, publicado recientemente y producto de una investigación de campo y de archivo de tres años en Sudáfrica y en otras regiones del subcontinente africano ${ }^{1}$, donde además participó en la conformación de un archivo de historia social y compartió conocimientos y destrezas en tareas administrativas ${ }^{2}$ y de reintegración social y personal con algunas comunidades.

Este libro tiene cuatro partes, cada una de ellas con extensa documentación histórica, viñetas etnográficas sugerentes y reflexiones provocativas para pensar comparativamente escenarios transcontinentales. La primera parte está dedicada a encuadrar lo que el autor denomina la ética de la colaboración, que supone enfrentar reflexivamente al antropólogo y a un buen número de los denominados expertos en traumas y violencias a una meditación sobre su "manía extractiva" de relatos y testimonios. Ética que supone, según la comprendo, un juego de espejos entre el valor hermenéutico de lo narrado para el experto y la densidad histórica de los silencios y los decires de los sobrevivientes, pero también entre lo callado intencionalmente y lo no revelado en

I. El libro fue premiado recientemente por la Fundación Alejandro Ángel Escobar en la categoría de mejor trabajo de investigación en ciencias sociales humanas. Esta Fundación otorga, desde el año 1955, los Premios de Ciencias y Solidaridad en Colombia. Se incluyen ciencias exactas, físicas y naturales, ciencias sociales y humanas y medioambiente y desarrollo sostenible.

2. Específicamente, su experiencia en el Direct Action Centre for Peace and Memory.

3. Por ejemplo, el Incidente del Caballo de Troya, ocurrido en la localidad segregada de Athlone, el I5 de octubre de I985, donde fueron asesinados tres niños y jóvenes entre once y veintiún años de edad. el relato. La segunda parte toma como pretexto analítico el acontecimiento sociohistórico de los Siete de Gugulethu, relacionado con el asesinato de siete jóvenes activistas en marzo de 1986 ocurrido en Ciudad del Cabo, y que terminó por inscribirse en la memoria colectiva de los sudafricanos, a diferencia de otros hechos también trágicos ${ }^{3}$ que no lograron sedimentarse como vehículos de la memoria, a pesar de que Sudáfrica es centro de múltiples tecnologías y escenarios del horror. Más allá de lo que han sugerido las comisiones de verdad, los juicios, los documentales y los memoriales alrededor de este icono del apartheid, el autor reconstruye y deconstruye las lógicas de representación que llevaron, por ejemplo, a la Policía y a los jueces a considerar en su momento a estos jóvenes como enemigos del régimen; pero también las maneras como se los nombró y 
Volumen 47 (I), enero-junio $20 I I$

confinó en los anales de la memoria, antes y después de la transición política que operó en Sudáfrica. Este episodio le sirve además para revelar las diversas estrategias y sentidos de inscripción que produjo la violencia del apartheid en los cuerpos, los lenguajes y los espacios en Sudáfrica.

La tercera parte muestra las prácticas de archivo y localización en varios momentos de la historia sudafricana reciente. Este capítulo puede leerse como una especie de descripción de las distintas "ofertas de sentido", tanto temporales como políticoinstrumentales, que emergen desde los Siete de Gugulethu. Es posible entender entonces por qué razones dicho episodio se inscribe en el pasado y en el futuro de un país, ya sea como tragedia o como nuevo comienzo. El autor refiere además los distintos discursos institucionales que van a alimentar esas ofertas de sentido. Por ejemplo, desde los discursos oficiales y durante los sombríos años del apartheid, el caso de los Siete de Gugulethu se inserta en el marco de la excepcionalidad y la seguridad nacional. A partir de los noventa, se reinscribe nuevamente en el denominado evangelio de la reconciliación, vehiculizado por la Comisión Nacional de Verdad y Reconciliación. Hoy, el mismo icono se resignifica una vez más a través de los usos sociales y políticos que hacen especialmente las madres y abuelas del Memorial Stone dedicado a las víctimas, y también a partir del despertar de la memoria en la lógica de la turificación $n^{4}$.

La cuarta parte cumple la función de cierre del argumento y el autor la dedica a analizar la noción de archivo, tomada del filósofo Jacques Derrida (I995), cuyo sentido y alcances antropológicos se transforman y adaptan para los objetivos intelectuales que se propone este trabajo. Aquí el autor reflexiona alrededor tanto del alcance ético-político de la inscripción, consignación

4. Con este neologismo me refiero a la inscripción y sedimentación de un lugar de memoria en un circuito de turismo.

5. El autor realizó labores de consultoría con la Comisión Peruana de la Verdad y la Reconciliación, e intercambió puntos de vista con colegas peruanos y comunidades de sobrevivientes y desplazados en Lima y Cuzco.

6. Además de su trabajo docente e investigativo en el Departamento de Antropología de la Universidad de los Andes, realiza actualmente una y legibilidad del dolor, como del desvanecimiento del mismo, realizado desde las denominadas tecnologías de tramitación que son, por ejemplo, las comisiones de verdad o los informes de verdad. Al final de este capítulo, el autor descentra su análisis de Sudáfrica y retorna a sus raíces sudamericanas para pensar América Latina, y en particular los casos de Perú ${ }^{5}$ y Colombia . 
Su apuesta se orienta a la ampliación del margen comparativo de su ejercicio etnográfico aunque, como lo reconoce, no logra profundizar lo suficiente en el caso colombiano, y deja de ese modo cuestiones abiertas que pueden abordarse en futuras indagaciones.

Mi percepción es que este libro puede ser leído desde varias perspectivas. De una parte, en tanto ejercicio de antropología del dolor (Tambiah, 1996), en el que se analizan las experiencias traumáticas de una sociedad, los patrones de sufrimiento, las modalidades de tramitación y los procesos de subjetivación presentes y futuros de los sobrevivientes. De igual forma, como un escrutinio reflexivo del oficio etnográfico en escenarios de aparente posconflicto. Especialmente en sociedades que, como la sudafricana, se encuentran aún escindidas entre las violencias de

consultoría para el Grupo de Memoria Histórica (ver siguiente nota), alrededor de una etnografía del proceso de versiones libres de miembros de las Autodefensas Unidas de Colombia, que relatan sus actividades ante un juez y un fiscal de Justicia y Paz, quien a su vez se encarga de investigar-corroborar la versión del testificante o versionado.

7. Esta área desarrolla sus actividades desde 2006 y está conformada por un grupo de dieciocho investigadores nacionales y un comité consultivo de ocho académicos extranjeros. Su principal objetivo es "elaborar y divulgar una narrativa global sobre el conflicto armado en Colombia". un pasado que no es lejano y las tramitaciones forzadas presentes. También como un ejercicio de convergencia entre una economía política de la experiencia de la víctima y del sobreviviente, una fenomenología de la violencia y una hermenéutica de la condición histórica. Quizá pueda leerse como la ampliación y el refuerzo de un trabajo previo que el autor había realizado en el norte de Colombia, con el propósito de descifrar la producción social de la otredad del desplazado forzado en medio de una red de discursos y prácticas de control institucionales, legales y sanitarias (Castillejo, 2000). Pero más allá de visibilizar lo sucedido en Sudáfrica o de las apuestas del autor por pensar el oficio etnográfico posconflicto, encuentro este texto particularmente relevante y apropiado, cuando se considera su contenido en clave de desciframiento político y hermenéutico, para abordar lo que ocurre hoy en Colombia alrededor de la recuperación del dolor de las víctimas y la reconstrucción de la memoria histórica del conflicto. Esta última lectura, aunque no es desarrollada por el autor en su texto, sí permite identificar nuevas vetas para reflexionar sobre los impactos de la tarea reconstructiva emprendida por el Grupo de Memoria Histórica ${ }^{7}$, en el marco de la reciente Ley de Justicia y Paz. 
Volumen 47 (I), enero-junio $20 I$

A propósito de las contribuciones del libro, quisiera mencionar rápidamente dos aspectos que considero sustanciales, y que se relacionan, primero, con el sentido ético-político y los alcances metodológicos de la producción de conocimiento sobre el pasado y el presente de violencia en Colombia; y, segundo, con la deconstrucción de los imaginarios sobre ciertas tecnologías de tramitación, especialmente las que despliegan las comisiones de verdad.

I. En un proceso como el de Justicia y Paz, sobre el cual se ha tenido que aprender y reaprender en el camino, no sobran las tensiones, las disputas y las escisiones entre las necesidades políticas decretadas oficialmente y las exigencias recreadas social-

- La metodología utilizada son los casos emblemáticos que permiten ilustrar, a partir de la reconstrucción de eventos y situaciones concretas de violencia vividas por determinadas comunidades, la magnitud de los conflictos, las disputas entre actores, las lógicas y mecanismos de terror, los impactos sobre la población y las iniciativas de resistencia. Desde 2008 hasta el presente, se han producido cinco informes sobre masacres (Trujillo, El Salado, La Rochela, Bojayá y Bahía Portete); tres informes temáticos (sobre memorias en tiempos de guerra, memoria y género en la costa Caribe y despojo de tierras) y unas herramientas metodológicas para reconstruir la memoria histórica. Para ampliar, se sugiere visitar http://www.memoriahistorica-cnrr.org.co

mente, alrededor de temas como la recuperación, la narración y la tramitación del pasado y del presente de nuestra violencia. En ese escenario hay varios actores y discursos. De una parte, se encuentran los miembros del Grupo de Memoria Histórica que están generando lecturas interpretativas globales y posicionando la tesis de que en nuestra historia reciente hay una especie de tránsito desde una guerra de combates hacia una guerra de masacres. Así lo revelan los informes emblemáticos sobre las masacres de Trujillo, El Salado, La Rochela, Bojayá y Bahía Portete. De otra parte, la denominada Ley de Justicia y Paz establece también una génesis del pasado que comienza en 1964, con la emergencia de la guerrilla de las Fuerzas Armadas Revolucionarias de Colombia (FARC), y un posible fin en 2005, con las políticas de cambio del gobierno de Uribe Vélez. Con esta Ley, se quiere posicionar en el imaginario nacional la idea de que estamos ante un horizonte transicional claro. Pero también están las organizaciones de víctimas, cuyas visiones sobre la memoria histórica disputan con las perspectivas oficiales, especialmente la manufacturación que la Ley de Justicia y Paz ha hecho en torno a cierto tipo de víctimas.

Estamos entonces de cara a un contexto con distintas formas de nombrar y manufacturar el pasado, variedad de actores, intereses y lógicas discursivas en juego. En ese sentido, el texto de 
Castillejo ayuda a esclarecer analíticamente el debate. Primero, porque advierte que de la manera como se nombre un pasado pueden derivar desvanecimientos o silencios. También, propone tener cuidado con la manía de la experticia, de interpretar y traducir el dolor, como si estuviéramos única y exclusivamente ante una industria extractiva y no frente a un escenario fenomenológico o experiencial. El asunto es que esta industria tiene enormes riesgos, los cuales no son debidamente ponderados en el debate público. Por ejemplo, al producirse un saber legible, el del experto, se puede terminar operando una nueva violencia, la simbólica, la de la inscripción, que desconoce el sentido profundo del silencio biográfico y comunitario. De ahí su propuesta de una ética de la colaboración o de la proximidad, que pasa también por procesos consultivos con las comunidades y los sobrevivientes, por aprendizajes y desaprendizajes, entre los que llegan de afuera en busca de relatos y los que, dentro de las comunidades, han padecido. Además, así como se archivan voces, también es posible excluir otras de las narrativas históricas. La industria extractiva también puede hacer creer que la naturaleza y efectos de la violencia quedan más o menos resueltos en la medida en que existan grupos de intermediarios especializados (sociólogos, historiadores, trabajadores sociales, psicólogos), prestos a solicitar y extraer el relato, salir de las comunidades y luego regresar con la compilación. La lectura de Castillejo nos invita a pensar sobre la responsabilidad de los académicos en medio de la guerra y a preguntar siempre, en una especie de terapia autorreflexiva, por la naturaleza de la producción del pasado y presente que se están archivando.

2. Las tensiones y disputas no se generan solo en el terreno de las lógicas discursivas sobre la naturaleza del pasado o la tarea reconstructiva de los expertos; también operan alrededor de los dispositivos transicionales, en este caso, las comisiones de verdad. De entrada es necesario reconocer que Colombia no tiene ni ha tenido en su historia una comisión de la verdad, si por ello se entiende un escenario que responda a la necesidad de esclarecimiento de hechos de violencia política en contextos de transición (Ceballos, 2009). Lo que tiene actualmente es una Comisión Nacional de Reparación y Reconciliación (CNRR), creada por la Ley 975 de 2005, con un encargo gubernamental de funciones extremadamente ambiciosas y complicadas por su naturaleza, para ser realizadas en tan solo ocho años. Entre ellas, acompañar los procesos de 
Volumen 47 (I), enero-junio $20 I$

desmovilización de grupos armados ilegales (paramilitares y guerrillas), facilitar la reincorporación de los mismos, atender de manera integral a las víctimas, ejecutar políticas de justicia y verdad y generar mecanismos de reparación simbólico-materiales para ellas. El modo en que está diseñada la CNRR impide que se convierta en una comisión de la verdad ${ }^{8}$. Entre la CNRR y el Área de Memoria Histórica (que hace parte de la CNRR) se tejen dos lecturas a veces contrapuestas del pasado, en la medida en que una tiende a generar, como se dijo arriba, un relato explicativo de nuestra guerra de masacres, y otra asume que estamos más del lado de la transición que del desangre latente. Aun así, a falta de comisiones de la verdad, hemos tenido algunas experiencias de comisiones extrajudiciales, escenarios creados durante el desarrollo del conflicto, independientemente de que en el horizonte exista un proyecto de transición o de que se logre pactar la paz entre las partes implicadas ${ }^{9}$ (cfr. Ceballos, 2009). De otra parte, también han sido comunes las comisiones de estudio de la violencia (Jaramillo, 20I0) ${ }^{10}$. Su objetivo primordial ha sido cartografiar y radiografiar el pasado o los pasados de nuestras violencias,

8. En 2009, la Corte Suprema de Justicia sugirió la creación de una comisión de la verdad. Su solicitud iba encaminada a esclarecer los crímenes cometidos por los paramilitares que se desmovilizaron al amparo de la Ley de Justicia y Paz. Este llamado se hizo en el marco de un serio cuestionamiento, luego de cuatro años, a la efectividad de los procesos judiciales amparados en esta Ley. Recientemente, el alto comisionado para la paz, Frank Pearl, aseguró que no se necesitaba una comisión de la verdad en el país, puesto que ya existía un Área de Memoria Histórica para ello, y crearla equivaldría a duplicar funciones innecesariamente (cfr. "No necesitamos una comisión de la verdad", 2010).

9. Por ejemplo, la Comisión para la Superación de la Violencia, de I99I; la comisión creada en I994 para investigar las masacres de Trujillo, entre I988 y I99I; la Comisión de la Verdad de los Hechos del Palacio de Justicia (2005). También existen otras, lideradas por sectores y organizaciones de la sociedad civil, como la Comisión Ética creada en 2006 por iniciativa del Movimiento Nacional de Víctimas de Crímenes de Estado (Movice).

Io. La Comisión Nacional Investigadora de las Causas y Situaciones Presentes de la Violencia en el Territorio Nacional (I958) y la Comisión de Estudios sobre la Violencia (I987). El Grupo de Memoria Histórica cumpliría también estas funciones. vehiculizando ofertas de sentido temporal en función del escrutinio público, a partir de unos informes nacionales con conclusiones y recomendaciones para los gobiernos de turno.

Ahora bien, aunque la perspectiva de Castillejo se ubica en la revisión crítica de las comisiones de verdad, en especial la sudafricana, su aporte resulta significativo para comprender de qué manera estos escenarios son marcos de representación del pasado, donde se instalan formas de narración oficial; donde la verdad factual que de ellas se deriva puede incidir en las posibilidades 
para concebir un futuro y pensar en la viabilidad de la reparación, tanto en el sentido fenomenológico, como en el político y legal. También nos ayuda a entender cómo estas comisiones se convierten en espacios rituales en los que se condensan ciertos silencios y tecnologías globales de tramitación local, cubiertas por un evangelio reconciliador global con expresiones y maquillajes locales que la mayoría de las veces tienen efectos muy precarios sobre las realidades nacionales, especialmente por las voluntades e intereses políticos que los motorizan. A través de dichas comisiones se archiva; se articulan, desarticulan y editan institucionalmente las lecturas sobre lo ocurrido. Un caso diciente de edición del pasado que anota Castillejo es el que operó en la Comisión Sudafricana con respecto al desplazado, que no fue considerado una víctima en el sentido oficial, y con la exclusión del debate público sobre la restitución de la tierra, que dejó intacto el fundamento mismo del apartheid. En el caso colombiano no estaríamos muy lejos de esa realidad. Es innegable que el nudo gordiano histórico de nuestra guerra es la tierra. Para muchos, entre los que me incluyo, además de ser el detonante de la violencia, la tierra podría ser la gran desactivadora del desangre. Pero en el actual proceso, parece que se conoce más de los crímenes que de la tierra usurpada. Y este es un silencio que no puede perdonársele a un proceso como Justicia y Paz, si se quiere avanzar en la reconciliación nacional.

Para concluir, es posible asumir que la apuesta de fondo de Castillejo con este interesante libro es desentrañar la geopolítica de la investigación, a través de la puesta en escena de una ética y una epistemología críticas del oficio. Para ello se requiere reflexionar sobre la relación entre colaboración e investigacion como un espacio de encuentro para el investigador, en el que se piensen las implicaciones de mirar sistémicamente y hacer inteligible aquello que constituye los puntos ciegos de la mirada, como lo dice Bateson (200I). Esa ética y esa epistemología suponen una confrontación de lo narrado por el experto, lo revelado por el activista, pero también de lo callado por los sobrevivientes. 


\section{ReFERENCIAS}

Bateson, G. (200I). Espíritu y naturaleza. Buenos Aires: Amorrortu Editores.

Castillejo, A. (2000). Poética de lo otro: una antropología de la guerra, la soledad y el exilio interno en Colombia. Bogotá: Instituto Colombiano de Antropología, Ministerio de la Cultura / Instituto Colombiano para el Desarrollo de la Ciencia y la Técnica.

Castillejo, A. (2009). Iluminan tanto como oscurecen: de las violencias y las memorias en la Colombia actual. Ponencia presentada en el foro nacional “¿Por qué recordar en Colombia?”, organizado por la Universidad Sur Colombiana y la Fundación Mundos Posibles, Neiva.

Ceballos, M. (2009). Comisiones de la verdad: Guatemala, El Salvador y Sudáfrica, perspectivas para Colombia. Bogotá: La Carreta.

DerRida, J. (1995). Archive Fever: A Freudian Impression. Baltimore: Johns Hopkins University.

JARAMILlO, J. (20IO). (en prensa). Narrando el dolor y luchando contra el olvido en Colombia. Recuperación y tramitación institucional de las heridas de la guerra. Revista Sociedad y Economía, I9.

No necesitamos una comisión de la verdad. (2010, I9 de junio). El Espectador.

TAmbiah, S. (1996). Leveling Crowds: Ethnonationalist Conflict and Collective Violence in South East Asia. Berkeley, Los Angeles, London: University of California Press.

JEFFERSON JARAMILlo Marín

Profesor, Departamento de Sociología Pontificia Universidad Javeriana jefferson.jaramillo@javeriana.edu.co / jefferson.jaramillo@flacso.edu.mx 